\title{
Diz eklemi çevresi kaynaklı deformitelerde kullanılmak üzere bir plak yapılanması
}

\author{
İran Esenkaya \\ Ortopedi ve Travmatoloji Uzmanı, Emekli Öğretim Üyesi \\ SANTE Tıp Merkezi, Ortopedi ve Travmatoloji Kliniği, İstanbul
}

A plate design to be used in deformities caused by the knee joint proximity

Mevcut buluş, tıp alanında, diz eklemi kaynaklı mekanik aks (eksen) bozukluğu yapan deformitelerde (şekil bozukluklarında) kullanılmak üzere bir plak yapılanması ile ilgilidir. Buluş, bilhassa tasarlanan forma göre özellikle eğim kazandırılmış bir plak, içerisinde enine olarak açılmış delikler ve kemiğe uygulandığı yüzey üzerinde uzanan özellikle üçgen şekline sahip destekleyici bloklar içeren bir plak yapılanması ile ilgilidir. Konuyla ilgili faydalı model dosyası paylaşılmıştır. Yapılan klinik ve biyomekanik çaIışmalar ile, proksimal tibia medial açık kama osteotomisi sonrası tespit için kamalı plak uygulaması ile yeterli stabilite elde edildiği gösterilmiştir.

Anahtar sözcülkler: faydalı model; diz eklemi; şekil bozukluğu; osteotomi; tespit; plak; kamalı plak

\section{T. C. Türk Patent Enstitüsü'ne Faydalı Model Belgesi için Başvuru Bilgileri[ ${ }^{[1]}$}

Başvuru bilgileri Tablo 1'de gösterilmiştir. ${ }^{[1]}$

Tablo 1. Başvuru bilgileri ${ }^{[1]}$

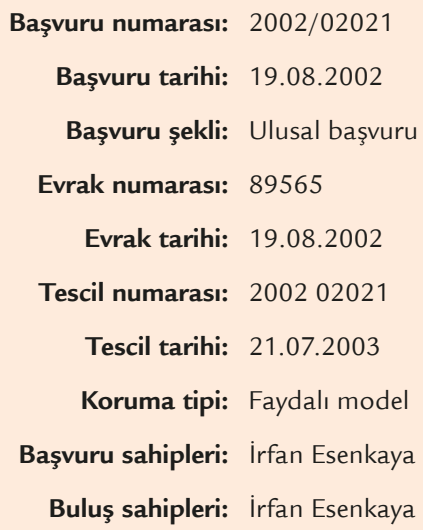

The present invention relates to a plate configuration for use in deformities that cause mechanical axis distortion caused by the knee joint in the medical field. In particular, the invention relates to a plate construction comprising a plate inclined in particular according to the designed form, holes drilled in it transversely, and supporting blocks, in particular triangular shaped, lying on the surface to which the bone is applied. The utility model file on the subject has been shared. With the clinical and biomechanical studies on the subject, it has been shown that sufficient stability is achieved with wedged plate application for fixation after proximal tibia medial open wedge osteotomy.

Key words: utility model; knee joint; deformity; osteotomy; fixation; plate; wedged plate
FAYDALI MODEL BELGESI - No: TR 200202021 Y[1] $^{[1]}$

\section{Teknik Alan ${ }^{[1]}$}

"Mevcut buluş, tıp alanında, diz eklemi kaynaklı mekanik eksen (aks) bozukluğu yapan şekil bozukluklarında (deformitelerde) kullanılmak üzere bir plak yapılanması ile ilgilidir. ${ }^{[1] "}$

\section{Önceki Teknik/Teknikler ${ }^{[1]}$}

“Günümüzde tıp alanında, şekil bozukluğu düzeltmek için kemik yüzeylerinin birbirinden uzaklaştırılarak araya bir plak yapılanmasının uygulandığı tespit sistemleri yaygın olarak kullanılmaktadır. ${ }^{[1,2]}$

Açık kama osteotomisi (opening wedge osteotomy) kullanılan bu cerrahi tekniklerden birisidir. Örneğin, kemik kesi yüzeyine destek sağlayıcı bloklu plak fikri Puddu tarafindan önerilmiş ve uygulanmıştır. Puddu yaklaşımına göre, ilki iki delikli olmak üzere ve sonradan geliştirilen

- İletişim adresi: Prof. Dr. İrfan Esenkaya, SANTE Tıp Merkezi, Ortopedi ve Travmatoloji Kliniği, Kalamış, Kadıköy, İstanbul Tel: 0532 - 3218681 e-posta: iesenkaya@hotmail.com ORCID iD: 0000-0002-7321-0012

- Geliș tarihi: 3 Kasım $2020 \quad$ Kabul tarihi: 16 Kasım 2020 
dört delikli plak üzerinde, kemik kesi yüzeyine yerleştirilen çeşitli yükseklik ve derinliklerdeki dikdörtgen bloklu düz plak ve vidalarla tespit sağlanabilmektedir. Bahsedilen uygulamada, özellikle tibia için kullanılan plağın düz olması yüzünden, kemikte kesinin yapıldı̆̆ı tibia proksimaline uyum sağlamada zorluklarla karşılaşılmış; bu yüzden söz konusu plak boyutlarını ufaltmak suretiyle sorunun çözümü yoluna gidilmiştir. Ayrıca, kemik kesisi ara yüzeyine yerleştirilen plağın blok kısmı solid (tek parça, içi dolu) olduğu için, metal bloğun hacmi kadar alanda kemik kaybı oluşmaktadır. ${ }^{[1,2]}$

Bunun yanında klasik uygulamalarda, mevcut plak yapılanmalarının kesilen kemiğin (tibia üst ucunun) eğimli yüzeyi üzerine arzu edilen şekilde yerleştirilememesi ve plak boyutunun artan yüksekliğine karşı istenen toleransın sağlanamaması gibi dezavantajlar ortaya konmaktadır. Yukarıda açıklanan nedenlerle, kemiğin bölgesel anatomik yapısına (eğimine) uygun bir plak yapılanması ihtiyaç olarak kendini göstermektedir." [1]

\section{Buluşun Kısa Tarifi ${ }^{1]}$}

"Yukarıda anlatılan istenmeyen durumların üstesinden gelebilmek üzere, buluşun amaçları[1];

- Kesilen kemik yüzeylerinin birbirinden uzaklaştırılarak, araya oto veya allo greftin yerleştirilebildiği bir kamalı plak yapılanması sunmaktır.

- Kemiğin bölgesel anatomik eğimine uygun, kesilen kemiğin üzerine tam olarak yerleşme yeteneğine sahip, kolay uygulanabilir bir plak yapılanması sunmaktır.

- Kesilen ve birbirinden uzaklaştırılan kemik yüzeylerine daha kuvvetli destek sağlayan bir plak yapılanması sunmaktır.

- Kolayca imal edilebilecek ve çok pratik kullanıma sahip bir plak yapılanması sunmaktır.

Bahsedilen amaçları gerçekleştirmek üzere oluşturulan plak yapılanması; tasarlanan şekle göre eğim kazandırılmış plak, içerisinde enine olarak açılmış delikler ve üzerinde uzanan destekleyici bloklar içermektedir. Kesilen kemik yüzeyine yerleştirilen bloklar özellikle üçgen şeklindedir. Düzeltilmek istenen şekil bozukluğunu açısı oranında bahsedilen bloklar (üçgen şeklindeki kamalar) arası örneğin 5, 7,5, 9, 10, 11, 12,5, 15 ve 17,5 mm yükseklikte olabilmektedir. ${ }^{[1]}$

Plağa kazandırılan eğim sayesinde yükseklik arttıkça kama şeklindeki bacakların plakla temas yeri birbirinden açılmaktadır (uzaklaşmaktadır). Bahsedilen eğim, uygulamaya maruz kalacak kemiğin anatomik eğimine uygun olarak hesaplanmaktadır. ${ }^{[1]}$

Buluş konusu yapılanma sayesinde, tibianın üst eklem yüzeyinin arkaya olan normal anatomik eğimini verebilecek şekilde farklı kama yüksekliklerinde iki delikli iki ayrı plağın da kullanılması mümkün olabilmektedir. Yani, plakların ikişer delikli şekilleri kullanılarak kemik kesisinin ön ve arka kısımlarına farklı kama yüksekliğinde plaklar kullanılarak tibial eğim verilebilmektedir. ${ }^{[1]}$

Kesilen kemik yüzeyine destek olan blok kısmı üçgen şeklinde tasarlandığından, aradaki kısımlar ameliyat sırasında greftle doldurulacaktır. Böylece aradaki kısımlara iyileşme döneminde kemik dokusu ilerleyecektir. ${ }^{[1]}$

Bahsedilen plakların kemiğe sabitlenmesini temin etmek üzere vida (sabitleme elemanı) kullanılmaktadır. ${ }^{[1]}$

Plak malzeme olarak ilgili standartlara uygun bir malzemeden, örneğin titanyum veya kobalt-krom (Co-Cr) karışımindan seri olarak üretilebilmektedir. ${ }^{[1]}$

Uygulama alanına örnek olarak, buluş konusu yapılanma alt ekstremitede diz eklemi kaynaklı mekanik eksen bozukluğu yapan şekil bozukluklarında, diz eklemindeki varus şekil bozukluğunda iç (medial), yine diz ekleminde valgus şekil bozukluğunda dış (lateral) taraftan açık kama osteotomisi şeklinde tibia veya femura uygulanan cerrahi yaklaşımlarda kullanılabilmektedir. ${ }^{[1]}$

Buraya kadar tüm bahsedilenlerden hareketle, mevcut buluşun sadece yukarıda sayılan ve aşağıda şekiller eşliğinde anlatılacak buluşa göre yapılanma örnekleriyle sınırlı tutulmaması gereği son derece açıktır. Tüm yapılan tanımlama ve örneklemeler ışığında, buluşun teknikte uzman kişilerce rahatça anlaşılabileceği göz önüne alındığında, buluş kapsamı ekteki istemler eşliğinde en geniş haliyle korunmalıdır. ${ }^{[1]}$

Örneğin söz konusu plak yapılanması, kesilen kemik yüzeylerinin birbirinden uzaklaştırılarak araya oto veya allo greftin kullanıldığı bir tespit sistemi olarak, özellikle tibiada kullanılmak üzere gerçekleştirilmiştir. Ancak kullanım alanı sadece bununla sınırlı kalmayıp alternatif bir tasarımla femura da açık kama osteotomisi uygulanabilmektedir. Uygulama alanına göre plak tasarım farklılıkları da gösterebilmektedir. ${ }^{[1]}$

Alternatif yapılanma olarak yine iskelet sisteminin diğer bölgelerini ilgilendirir metafizer bölge kaynaklı şekil bozukluklarının düzeltilmesinde kama yüksekliği ayarlanan bu plaklar özel olarak imal edilerek uygulanabilir. [1]"

\section{Buluşun Detaylı Açıklanması [1]}

"Şekillerdeki (parçaların) referans numaraları: (1) Tibial ve femoral plaklar, (2) Delikler, (3) Destekleyici bloklar/üçgen kamalar. ${ }^{[1] "}$

"Şekil 1a'da buluşa göre tercih edilen dört delikli (geniş) bir tibial plak yapılanmasının önden görünümü temsili olarak resimlenmiş durumdadır. Görüleceği üzere tibial plak (1), içerisinde enine olarak açılmış delikler (2) ve üzerinde uzanan destekleyici bloklardan (3) oluşturulmaktadır. Bahsedilen plağa (1) özellikle bir eğim verilmektedir. ${ }^{[1]}$ 
Şekil 1b'de daha iyi görüleceği üzere, bahsedilen destekleyici bloklar (3) standartlara uygun olarak örneğin 5, 7,5, 9, 10, 11, 12,5, 15 ve 17,5 mm yükseklikte, 4-5 mm derinlikte yapılabilmektedir ve özellikle üçgen şeklindedir. Burada, düzeltilmek istenen şekil bozukluğu, önceden hesaplanarak uygun kama (3) yüksekliklerine sahip, örneğin 6, 14 veya $16 \mathrm{~mm}$ gibi plaklar da üretilebilmektedir. Eğim tercihe bağlı olmakla beraber yaklaşık $10^{\circ}$ 'dir. Buluşa göre dört delikli plak yapılanmasında bahsedilen kamalar (üggen destekler) (3) tamamen plağın (1) eni boyunca uzanmamaktadır; buradaki amaç, ara bölgede kemik dokusunun ilerleyebilmesine imkan tanınmasıdır. ${ }^{[1]}$

Şekil $2 a$ ve $2 b^{\prime}$ de verilen iki delikli (dar) tibial plak ise buluşa göre alternatif bir yapılanma olup aynı özellikleri taşımaktadır. Ancak, görüleceği üzere buluşa göre üçgen kamalar (3) plağın (2) eni boyunca uzanmaktadır. ${ }^{[1]}$

Şekil $3 a$ ve $3 b^{\prime}$ de ise başka bir alternatif olarak yedi delikli femoral plağın (1) önden ve yandan görünümleri temsili olarak resimlenmiş durumdadır. Söz konusu destekleyici bloklar (3) önceden bahsedilenlerle aynı ölçütlere sahip olabilmektedir. Femurun distal eğimine uygun olacak şekilde, plak (1) üretim aşamasında eğilerek şekillendirilmiştir. ${ }^{[1]}$

Şekillerde gösterilmemiş olmasına karşın, gerek tibial gerekse femoral plakların kemiğe sabitlenebilmesi için önceki teknikten bilinen vidalar kullanılmaktadır. Bunların tümü yivli, normal başlı veya düşük profilli, uygun uzunlukta vidalardır. Örneğin burada spongioz vidalar kullanılabilmektedir. Distal (vidalar) olarak kortikal vidalar da uygulanabilmektedir. ${ }^{[1]}$

Plak (1) genişliği plak/kemik uyumunu sağlamak üzere çok sert olmayacak bir yapıda belirlenmektedir. Plak malzeme olarak örneğin titanyum veya kobalt-krom (Co-Cr) karışımından üretilebilmektedir. ${ }^{[1] ”}$

\section{Buluşun Açıklamasına Yardımcı Olacak Şekiller ${ }^{[1]}$}

(a)

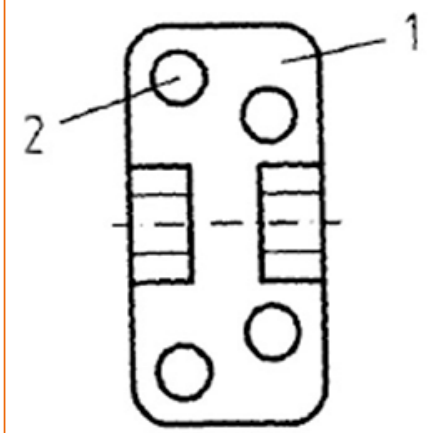

(b)

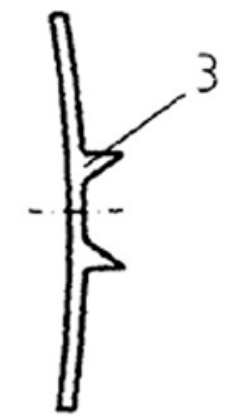

Şekil 1. a, b. Buluşa göre dört delikli (geniş) tibial plak yapılanmasının önden (a) ve yandan (b) görünümleri. ${ }^{[1]}$

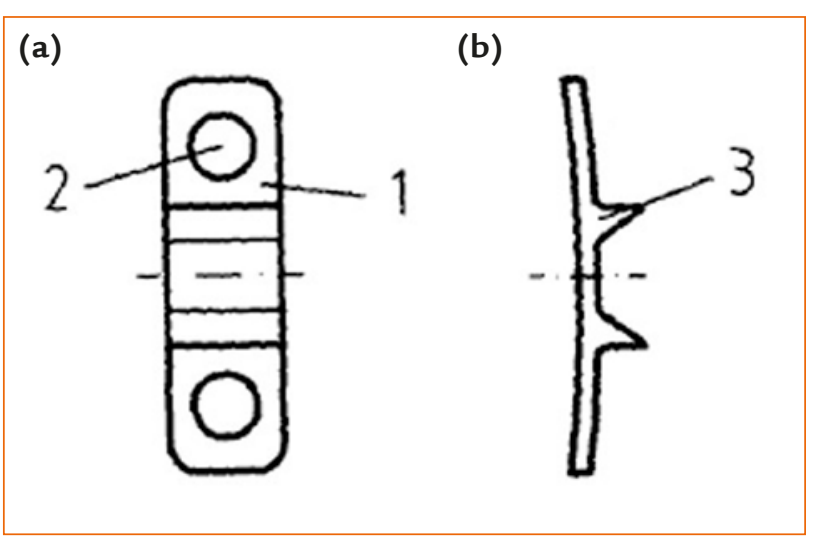

Şekil 2. a, b. Buluşa göre iki delikli (dar) tibial plak yapılanmasının önden (a) ve yandan (b) görünümleri. ${ }^{[1]}$ (a)

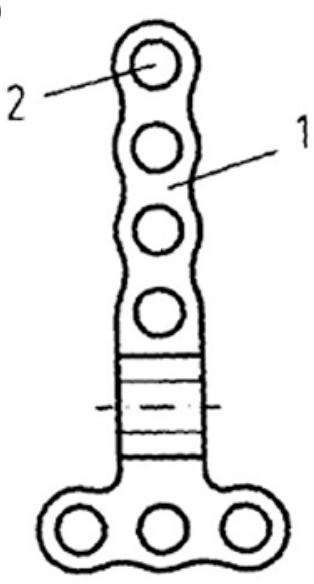

(b)

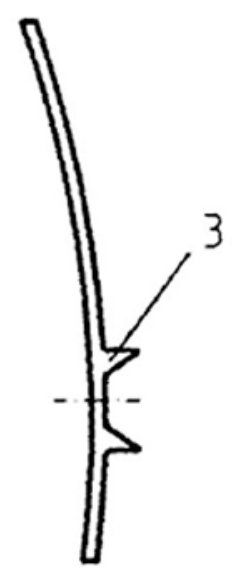

Şekil 3. a, b. Buluşa göre yedi delikli femoral plak yapılanmasının önden (a) ve yandan (b) görünümleri. ${ }^{[1]}$

\section{İstemler ${ }^{[1]}$}

"1. Diz eklemi kaynaklı mekanik eksen bozukluğu yapan şekil bozukluklarında (deformitelerde) kullanılmak üzere bir plak yapılanması olup, tasarlanan forma göre özellikle eğim kazandırılmış bir plak, içerisinde enine olarak açılmış delikler ve üzerinde uzanan destekleyici bloklar içermektedir.

2. Istem 1'e göre bir plak yapılanması olup bahsedilen destekleyici blokların (3) özellikle üçgen şeklinde olmasıyla karakterize edilmektedir.

3. İstem 1'e göre iki delikli (dar) bir plak yapılanması olup bahsedilen destekleyici blokların (3) plağın eni boyunca uzanmasıyla karakterize edilmektedir.

4. İstem 1'e göre dört delikli (geniş) bir plak yapılanması olup bahsedilen destekleyici blokların (3) araya kemik ilerlemesini sağlayacak şekilde plağın her iki tarafinda konumlandırılması ve orta kısmın düz olmasılla karakterize edilmektedir. 
5. Önceki istemlerden herhangi birine göre bir plak yapılanması olup bahsedilen plağın (1) kama (3) bacakları arası mesafe arttıkça plak boyunun artmasıyla ve verilen eğim sayesinde plak-kemik uyumunun sağlanabilmesiyle karakterize edilmektedir.

6. Önceki istemlerden herhangi birine göre bir plak yapılanması olup bahsedilen eğimin, uygulamaya maruz kalacak kemiğin ĕgimine uygun olmasıla karakterize edilmektedir.

7. Önceki istemlerden herhangi birine göre bir plak yapılanması olup bahsedilen destekleyici blokların (3) düzeltilmek istenen şekil bozukluğu önceden hesaplanarak uygun kama yüksekliklerinde, örneğin standartlara uygun olarak 5, 7,5, 9, 10, 11, 12,5, 15, 17,5 mm yükseklikte, 4-5 mm derinlikte olmasıyla karakterize edilmektedir." [1]

Şekil 4'te; iki delikli dikdörtgen, dört delikli dikdörtgen, konik ve ters " $L$ " şeklindeki titanyum malzemesinden üretilmiş plaklara ait görünümler verilmiştir.

\section{YAZARIN KONUYLA ILGILI ÇALIŞMALARI}

Diz eklemi çevresindeki şekil bozuklukları (deformiteler), femur veya tibiadan kaynaklanmak üzere frontal (koronal), sagittal ve/veya aksiyel (horizontal) planlarda tek başlarına veya birlikte olabilir. Bunlar frontal planda varus ve valgus deformitesi, sagittal planda fleksiyon -ekstansiyon deformitesi ile tibial slop (eğimin) artması ya da azalması şeklinde olabilir. Diz ekleminde, proksimal tibiofibular eklemi hariç tutarsak; medial tibiofemoral, lateral tibiofemoral ve patellofemoral olmak üzere üç kompartman vardır. Genç ve aktif hastalarda patellofemoral eklem dışında, medial ya da lateral tibiofemoral kompartmanlardan sadece birindeki osteoartritik değişikliklere ilave olarak diz eklemi çevresinde sırasıyla genu varum ya da genu valgum şeklinde şekil bozukluğu olduğunda, düzeltici osteotomi uygulamaları günümüzde oldukça kabul görmüştür. Mekanik ya da anatomik eksene göre değerlendirilen diz eklemi çevresindeki açısal
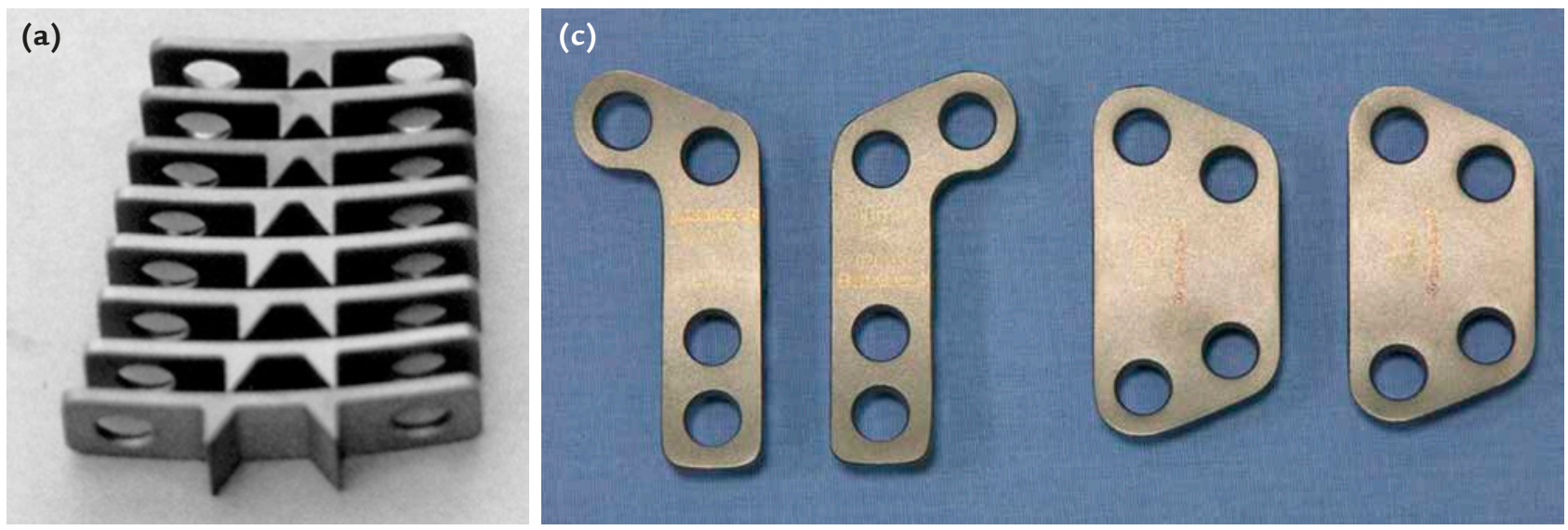

(b)
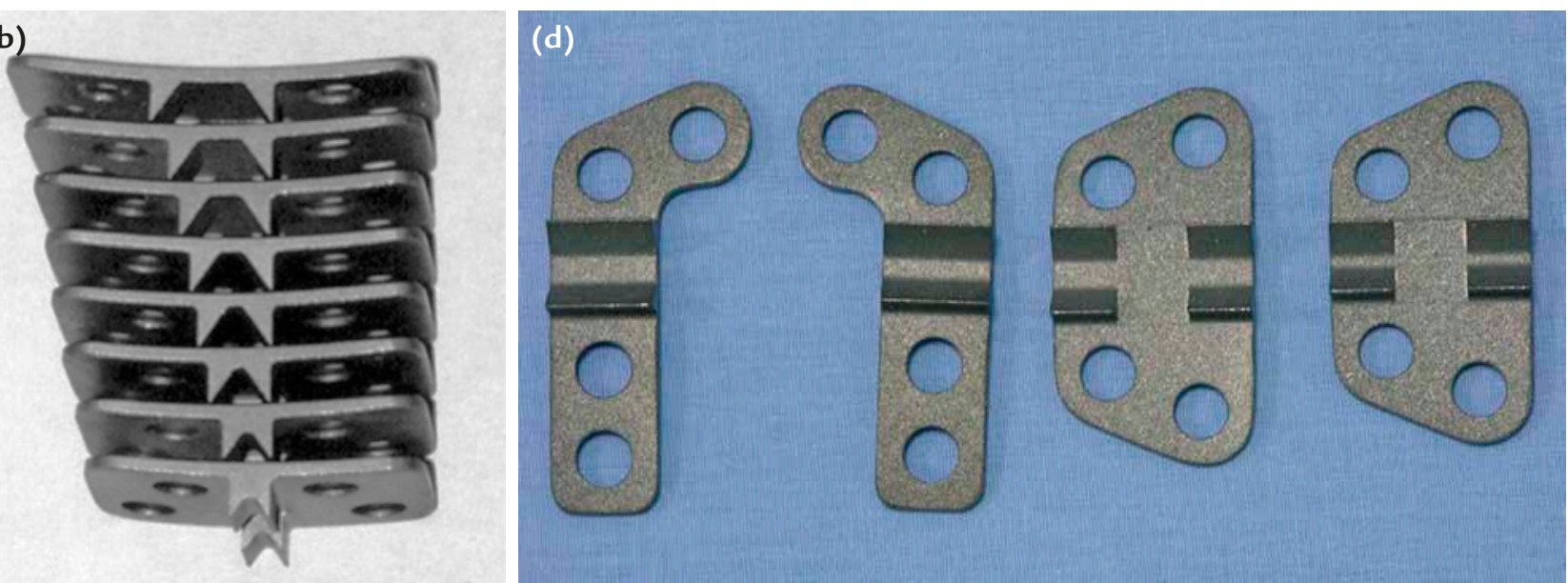

Şekil 4. a-d. íki delikli kamalı plakların yandan ve önden (iç taraftan) (a); dört delikli, dikdörtgen şeklindeki kamalı plakların yandan ve önden (iç taraftan) (b); dört delikli, ters "L" ve konik şekilli kamalı plakların dış taraftan (c) ve dört delikli, ters "L" ve konik kamalı plakların önden (iç taraftan) (d) görünümleri. 

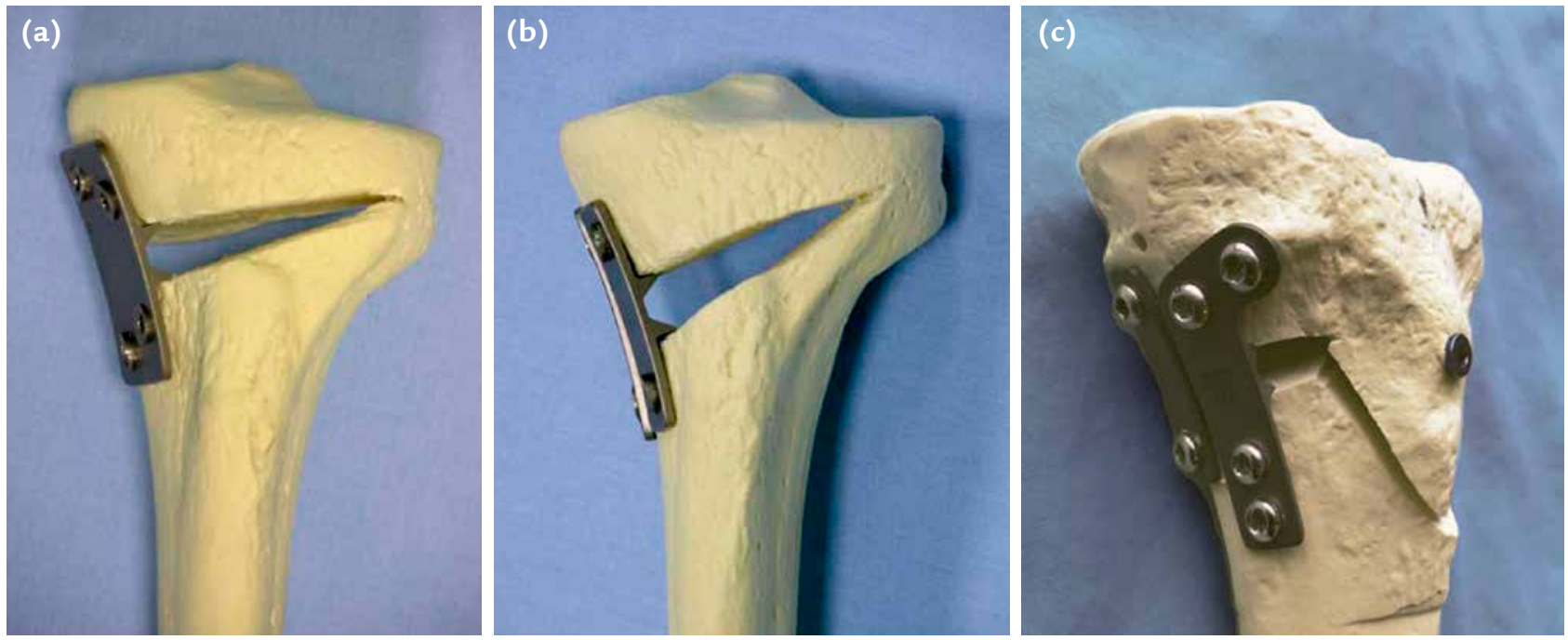

Şekil 5. a-c. Tek düzlemde medialden yapılan osteotomide tespit için dört delikli dikdörtgen şeklindeki tek plak (a) ve iki delikli dikdörtgen şeklindeki iki plak (b) uygulaması. İki düzlemde medialden yapılan osteotomide ön tarafa ters "L" şeklindeki ve arkaya da iki delikli dikdörtgen şeklindeki plak uygulaması (c).

uyum bozukluklarının femur distali ya da tibia proksimalinden oluşuna göre farklı osteotomi yöntemleri uygulanmaktadır. Düzeltici osteotomiler başarı oranları yüksek uygulamalardır ve kemik yapı hastada bırakıldığı için biyolojik yöntemlerdir. Osteotomi sonrası kullanılan tespit malzemesinin stabilite özelliği uygulanan tekniğin başarısını ve hastanın memnuniyet oranını artırmaktadır. ${ }^{[2-13]}$

Tibia proksimalinden kaynaklanan şekil bozukluklarında medial açık kama ostetomisi yaygın olarak kullanılmaktadır. Teknik mediaden tek planda (monoplanar) ${ }^{[2-8]}$ veya iki planlı (biplanar retrotüberkül) ${ }^{[8-13]}$ olarak uygulanabilir (Şekil 5). Yazar tespit için, tasarımını oluşturduğu iki veya dört delikli, dikdörtgen, konik ya da ters " $L$ " şeklindeki plaklardan birini veya ikisini kullanmaktadır (Şekil 4 ve 5). ${ }^{[3-13]}$ Kıyaslamalı biyomekanik çalışmada; dikdörtgen şeklindeki dört delikli plağın $6443,3 \pm 1383,5 \mathrm{~N}$, dikdörtgen şeklindeki iki delikli iki plağın 8460,0 $\pm 1756,5 \mathrm{~N}$, ters “L" şeklindeki dört delikli plağın 7963,0 $\pm 1797,9 \mathrm{~N}$ ve ters " $L$ " şeklindeki dört delikli plak ile birlikte dikdörtgen şeklindeki iki delikli plağın birlikte kullanılması durumunda 13320,0 $\pm 3544,7 \mathrm{~N}$ yüke kadar dayanıklılık gösterdikleri saptanmıştır. ${ }^{[14]}$ Yazarın deneyiminde, 2001 Ekim ayındaki ilk olguda tespit için dikdörtgen şeklindeki plak uygulamasından bu güne geçen süreç içerisinde sadece bir vida kırığı oluşmuştur. Hiçbir plakta eğilme ya da kırılma oluşmamıştır. Osteotomi yüzeylerini içeriden destekleyen üçgenimsi kemik kamalar hem yeterli destek sağlamaktadır, hem de bu bölgede kaynama süreci sonunda, kamaların arası kemik dokusuyla dolduğu için, medial kortekste sadece kamanın hacmi kadar minimum kemik kaybı oluşturmaktadır. Sonuç olarak; proksimal tibia medial açık kama osteotomisinde tespit için farklı şekillerde ve farklı kama yüksekliklerindeki kamalı plakların tek başlarına ya da birlikte kullanılmaları sonrası yeterli tespit elde edilmiştir. ${ }^{[3-14]}$

Plaklar daha sonra (yazarın oğlu; Esenkaya, Tayfun) “Eskata Proksimal Tibia Osteotomi Plağı” adı altında üretilmiştir (TIPSAN).

\section{KAYNAKLAR}

1. Diz eklemi çevresi kaynaklı deformitelerde kullanılmak üzere bir plak yapılanması. T. C. Türk Patent Enstitüsü. Faydalı Model belgesi. No: TR 200202021 Y. https://portal. turkpatent.gov.tr/anonim/arastirma/patent/detayli

2. Franco V, Cerullo G, Cipolla M, Gianni E, Puddu G. Open wedge high tibial osteotomy. Techniques in Knee Surgery 2002;1:43-53. Crossref

3. Esenkaya İ. Fixation of proximal tibia medial opening wedge osteotomy using plates with wedge [Proksimal tibia medial açık kama osteotomisinde kamalı plak uygulaması]. Acta Orthop Trauma Turc 2005;39:211-23. https://www.aott. org.tr/en/fixation-of-proximal-tibia-medial-opening-wedgeosteotomy-using-plates-with-wedges-164753

4. Esenkaya i. Proksimal tibia medial açık kama osteotomisi. TOTBID Derg 2005;4:1-14. http://www.totbid.org.tr/files/ ONLIB/4_1/2.pdf

5. Esenkaya i, Elmalı N. Proximal tibia medial open-wedge osteotomy using plates with wedges: early results in 58 cases. Knee Surg Sports Traumatol Arthrosc 2006;14:955-61. Crossref 
6. Esenkaya i. Opening wedge proximal tibial osteotomy using the platewithwedge. Tech KneeSurg2006;5:261-73. https://insights. ovid.com/techniques-knee-surgery/tecks/2006/12/000/ opening-wedge-proximal-tibial-osteotomy-using/9/00132588

7. Elmalı N, Esenkaya i. Proksimal tibia medial açık kama ostetomisi. Turkiye Klinikleri J Orthop \& Traumatol-Special Topics 2013;6:70-8. https://www.turkiyeklinikleri.com/article/ tr-proksimal-tibia-medial-acik-kama-osteotomisi-67898.html

8. Esenkaya i, Ünay K. Proksimal Tibia Mediyal Açık Kama Osteotomisi (Bölüm 6). İçinde: Sur H, editör. Yüksek Tibial Osteotomi. Ankara: TOTBID Yayınları; 2014. s.49-62.

9. Esenkaya i, Ünay K. Proximal medial tibial biplanar retrotubercle open wedge osteotomy in medial knee arthrosis. Knee 2012;19:416-21. Crossref

10. Elmalı N, Esenkaya I, Can M, Karakaplan M. Monoplanar versus biplanar medial open-wedge proximal tibial osteotomy for varus gonarthrosis: a comparison of clinical and radiological outcomes. Knee Surg Sports Traumatol Arthrosc 2013;21:2689-95. Crossref
11. Esenkaya i, Ünay K, Türkmen i. Medial gonartrozda retrotüberkül açık kama ostetomisi. Turkiye Klinikleri J Orthop \& Traumatol-Special Topics 2013;6:79-85. https:// www.turkiyeklinikleri.com/article/tr-medial-gonartrozdaretrotuberkul-acik-kama-ostetomisi-67899.html

12. Esenkaya I, Poyanlı O, Gökçen HB. İki planlı "Retrotüberkül” Medial Açık Kama Valgus Osteotomisi ve Kamalı Plak Uygulaması (Bölüm 14). İçinde: Esenkaya I, Özenci $M$, Kocabey Y, Bombacı H, Köse Ö, editörler. Diz Çevresi Osteotomileri. İstanbul: İstanbul Tıp Kitapevleri; 2018. p.115-25.

13. Esenkaya i, Özturan B. Proksimal tibia medial açık kama iki planlı retrotüberkül osteotomisi: kamalı plak ile tespit. TOTBID Derg 2020;19:399-408. Crossref

14. Esenkaya i, Mısırlıoğlu M, Keleştemur MH, Elmalı N, Fadıllıoğlu E. Biomechanical evaluation of different fixation plates in medial opening upper tibial osteotomy. Knee 2007;14:46-50. Crossref 